\title{
Editorial
}

\section{Ethical marketing in financial services: The continuing importance of fiduciary responsibility}

For some time now, the media spotlight has been focused sharply on the financial services sector. Of course, this has had a lot to do with the growth in size and significance of the sector as a key component of the UK economy, but there have also been less positive reasons for the attention. The reputations of the sector and the organisations within it have suffered due to the many allegations and evidence of products being mis-sold and what is termed 'bad advice' provided to consumers.

We have a situation where the previously unquestioned ethical behaviour of financial services organisations has been questioned and, not surprisingly, this has had repercussions for consumers who may well feel they can no longer rely on the advice they receive from their financial advisers. The consequences have been no better for organisations within the sector whose reputation for honesty, integrity and reliability has suffered.

Clearly this has implications for generation of business and profitability just as it has for the buying behaviour of consumers. In this latter connection, consumers may be unwilling to purchase products or seek advice from a financial services organisation unless they have received a favourable report on its reliability from a trusted source of reference such as a relative or a friend, perhaps with some perceived expertise in the field.

If it is the case that confirmation of sound ethical behaviour or, at least, reliability of advice, is of significant importance to the consumer, it seems reasonable to conclude that the organisation which can demonstrate these qualities might well improve its competitive position. There can be little doubt that this would be a good thing in what is a very competitive market place and where it is generally recognised that differential advantage can be difficult to achieve and sustain. Unfortunately, although it may well be that opportunities for competitive advantage are available to the provider who has developed a reputation for honesty and reliability, it is arguably quite difficult to generate such a reputation in the current climate.

All of this, of course, presumes that honesty and integrity are particularly important features of financial services marketing but many people feel, quite reasonably, that ethical behaviour is important in marketing regardless of the business sector. At the same time, though, particular reference has been made in the literature to the requirement for the financial services provider to meet their fiduciary responsibility or their duty of good faith to the consumer. The suggestion is that such a duty of good 
faith is more important within financial services than with other products in other sectors and the question then arises as to why this should be. There are various reasons:

- the perceived complexity of the product range and product characteristics;

- the substantial number of providers and the competition for business which results from this;

- asymmetry of information between provider and consumer. When combined with the intangibility of the product offering, the consumer may have to place substantial reliance on the quality and reliability on the information and advice given by the provider;

- the need to compete effectively and generate sales and profitability which has resulted in development of a sales culture in the sector. It is often the case that financial sales employees rely on commission to supplement their income;

- the financial implications of the purchase in terms of price and future financial well-being of the consumers;

- the fact that there is little opportunity for evaluation of the product prior to purchase and that there is often a timelag between purchase and receipt of benefits.

There will be other reasons and it may even be that there is a lack of interest on the part of the consumer in the purchase of financial products. It is not as much fun to buy a pension plan as it is to buy a new car or new clothes. This lack of enthusiasm for the transaction may well lead to a greater willingness to seek out the advice of the provider, as long as it is reliable.

This situation has the potential to present substantial difficulties for the consumer in making the purchase decision and for providers in generating sales to consumers who may not trust them. The government has directed its attention towards addressing the problem through the establishment of the Financial Services Authority and the introduction of the Financial Services and Markets Act 2000 and, in both cases, protection of the consumer and regulation of the provider's behaviour are a priority. Despite this, however, the suggestions are that the reputation of the industry remains tarnished and consumers require a considerable degree of reassurance about a provider's honesty and reliability before they will consult them for advice. Consequently, the consumer has to obtain this reassurance while making a decision to purchase and the provider must convince the consumer that they are an 'honest broker'.

In consideration of this whole subject, the author has undertaken some limited research into ethical marketing within financial services and the continuing importance of fiduciary responsibility. This work considered the following issues:

- the reasons why fiduciary responsibility should be delivered by the financial services provider;

- the extent to which that fiduciary responsibility should be and continues to be expected by the financial services consumer;

- the extent to which the sector meets its fiduciary responsibilities;

- the extent to which trust is the key component in the consumer's decision to select a provider.

The sample size was small and, consequently, substantive claims cannot be made for the validity of the findings. Since a number of similar points were made by the respondents, however, it was felt that 
some conclusions could reasonably be drawn from the views expressed.

These conclusions were as follows:

- Consumers continue to have a high expectation that financial services providers should meet their fiduciary responsibility. It remains an important component of financial services marketing and it was felt to be more critical to the financial services purchase than to other consequential purchases for the reasons referred to above.

- There was considerable dissatisfaction with the performance of the financial services sector with regard to ethical behaviour. In particular, there was a clear perception that the sector could not be relied upon to meet its fiduciary responsibility to the extent that was once the case.

- The selection of provider is of critical importance to the consumer.

Specifically, some form of reassurance or reference that the provider is honest and reliable is essential before a provider is used or a purchase made. Word-of-mouth recommendations are of particular significance with smaller providers and relatively important to supplement the comfort provided by the reputation of larger organisations.

- Due to the substantial concern about the extent to which financial services providers meet their fiduciary responsibility, providers would only be chosen on the strength of a reliable reference. With that reference, however, experience was good and there was no strong indication from the research that providers behaved unethically.

- Following on from the last point, there was a suggestion that, in many cases, the mistrust of the sector was misplaced and substantial efforts had been made to improve the sector's ethical performance. The indications from the research were, however, that this message needs to be conveyed to consumers much more clearly.

- It seems reasonable to conclude that opportunities for competitive advantage are available to the provider who has developed a reputation for honesty and reliability. At the same time, it may be difficult to generate such a reputation. It may be that smaller providers, such as independent financial advisers, need to concentrate their attention on consumers who know and trust them in the hope that their recommendations will lead to more business.

- It is possible that, due to this requirement for a reliable recommendation, there is little obvious benefit to be gained from advertising in the press or other media. The indications from the respondents were that there were no circumstances in which they would select an adviser purely on the basis of such advertising. Word-of-mouth publicity was much more important.

Overall, there was considerable support for the conclusion that the extent to which the provider meets their fiduciary responsibility continues to be important to the financial services consumer.

Consequently, it remains an important component of financial services marketing and a significant influence on buying behaviour. In particular, it is a key factor, and in certain cases, the key factor, in the consumer's selection of a financial services provider.

On the bright side, despite considerable damage to the sector's reputation in recent years, there are indications that improvements have been made in the extent to which the duty of good faith is being met by organisations.

Unfortunately, these improvements may not have been enough to convince 
consumers and considerable work may still be required to demonstrate that the sector's word is still its bond. In this connection, research could at least guide organisations on the action which needs to be taken to restore consumers' faith in the financial services sector. Some areas which might usefully be investigated are:

- the principal criteria used by consumers in determining whether they feel a financial services provider is trustworthy;

- the role of reference groups in influencing the buying behaviour of financial services consumers in their search for a reliable provider;
- the action which financial services organisations can take to demonstrate that they are honest, that their advice is reliable and that their products are suitable for consumers' need.

\section{Stewart Falconer Napier University \\ UK}

\section{Reference}

1 Falconer, S. C. (2001) 'My Word is my Bond, or is it? - Ethical Marketing in Financial Services - The Continuing Importance of Fiduciary Responsibility', The Robert Gordon University, Aberdeen, UK. 